\title{
氧化钼电致变色材料与器件
}

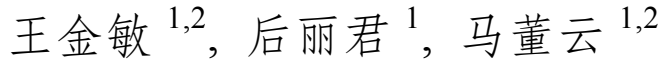 \\ (1. 上海第二工业大学 工学部, 环境与材料工程学院, 上海 201209; 2. 上海理工大学 理学院, 化学系, 上海 200093)
}

摘 要: 电致变色材料具有可逆的颜色转变特性, 在智能窗、显示器、防眩后视镜、电子纸、军事伪装等领域应用 广泛。相对于其它种类的显示器件, 电致变色显示器件具有色彩丰富、对比度高、无视盲角、断电后仍显色等优点。 作为一种典型的阴极着色电致变色材料, 氧化钼具有响应时间短和着色态更接近于人眼对光线的敏感波段等优点, 使得由氧化钼组成的电致变色器件具有重要的研究价值。本文简要介绍了电致变色、电致变色材料与器件的定义 及其应用, 尤其电致变色技术最近在智能手机上得到了示范应用, 表明电致变色技术未来有良好的发展前景。然后, 详细综述了氧化钼薄膜的制备、氧化钼的改性、氧化钼电致变色器件的研究进展。最后提出了氧化钼电致变色薄 膜与器件当前存在的问题和解决的途径, 并对其发展前景进行了展望。

关 键 词: 氧化钼; 电致变色; 掺杂; 复合; 综述

中图分类号: TQ174 文献标志码: A

\section{Molybdenum Oxide Electrochromic Materials and Devices}

\author{
WANG Jinmin $^{1,2}$, HOU Lijun ${ }^{1}$, MA Dongyun ${ }^{1,2}$
}

(1. School of Environmental and Materials Engineering, College of Engineering, Shanghai Polytechnic University, Shanghai 201209, China; 2. Department of Chemistry, College of Science, University of Shanghai for Science and Technology, Shanghai 200093, China)

\begin{abstract}
Electrochromic materials show reversible color-changeable characteristics, which are widely used in smart windows, displays, adjustable reflective mirrors, electronic paper, military camouflage and other fields. Compared with other kinds of display devices, electrochromic display devices have advantages of multi-colors, high contrast, no blind visual angles, and maintainable color after power off. As a typical cathodic colored electrochromic material, molybdenum oxide exhibits advantages of short response time and colored state closer to the sensitive wavelength band of the human eye to light, so that the electrochromic devices composed of molybdenum oxide is important in the research. This paper briefly introduces the definitions and applications of electrochromism, electrochromic materials and devices. In particular, electrochromic technology recently realized a demonstration application in smart phones, indicating the good prospects for the future development of electrochromic technology. We summarized mainly the research progress of the preparation of molybdenum oxide films, the modification of molybdenum oxide, and the molybdenum oxide based electrochromic devices. Finally, we presented current existing problems and solutions to molybdenum oxide based electrochromic films and devices with development
\end{abstract}

收稿日期: 2020-07-24; 收到修改稿日期：2020-09-17; 网络出版日期：2020-11-05

基金项目：国家自然科学基金(61775131，61376009); 上海高校特聘教授(东方学者)岗位计划(2013-70); 上海第二工业大学 研究生项目基金(EGD19YJ0039)

National Natural Science Foundation of China (61775131, 61376009); Program for Professor of Special Appointment (Eastern Scholar) at Shanghai Institutions of Higher Learning (2013-70); Shanghai Polytechnic University Graduate Project Fund (EGD19YJ0039)

作者简介：王金敏(1975-)，男，教授.E-mail: wangjinmin@sspu.edu.cn; jmwang@usst.edu.cn WANG Jinmin (1975-), male, professor. E-mail: wangjinmin@sspu.edu.cn; jmwang@usst.edu.cn 
prospects.

Key words: molybdenum oxide; electrochromism; doping; composite; review

电致变色是指在电场作用下, 材料的颜色或光 学性能发生可逆变化的现象 ${ }^{[1-4]}$ 。具有电致变色性 能的材料称为电致变色材料, 这些材料组装成的器 件称为电致变色器件。目前, 电致变色技术在智能 窗、显示器、防眩后视镜、电子纸、军事伪装等领 域都有广泛的应用前景 ${ }^{[5-9]}$ 。随着科技的不断发展, 电致变色技术的应用领域日新月异。相对于其它种 类的显示器件, 电致变色显示器件具有色彩丰富、 对比度高、无视盲角、断电后仍显色等优点 ${ }^{[10]}$ 。最 近在智能手机领域, 一加手机推出了首款概念手机 OnePlus Concept One, 首次利用电致变色技术, 实 现了“潜隐式后摄” 的效果, 将摄像头巧妙地隐藏起 来。Vivo 手机厂商官方宣布了手机背盖的电致变色 技术，用户可根据自身喜好定义多种手机配色，实 现“千人千面”。这种依托于电致变色技术的手机或 将引领智能手机行业的新潮流, 从而推动电致变色 技术进一步走进大众视野。

\section{1 电致变色材料与器件}

\section{1 电致变色材料}

自 20 世纪 60 年代, Platt ${ }^{[11]}$ 在研究有机染料时首 次发现电致变色现象以来, 研究人员对电致变色现 象进行了大量的研究, 极大地丰富了电致变色材 料。电致变色材料可分为有机电致变色材料与无机 电致变色材料。有机电致变色材料颜色种类多、光 学性能好、变色速率快, 但易老化和氧化, 典型代表 有紫罗精类化合物 ${ }^{[12-13]}$ 、导电聚合物 ${ }^{[14-15]}$ 。无机电 致变色材料优点是结构与性能稳定性好, 缺点是颜 色单一，典型代表有 $\mathrm{WO}_{3}{ }^{[16]} 、 \mathrm{MoO}_{3}{ }^{[17]} 、 \mathrm{NiO}^{[18]}$ 等。 根据着色电位的不同, 即发生电化学氧化还原反应 时是氧化态着色还是还原态着色, 电致变色材料可 分为阳极电致变色材料和阴极电致变色材料。

氧化锄 $\left(\mathrm{MoO}_{3}\right)$ 作为一种低成本的过渡金属氧 化物, 有着较高的电化学活性, 在电致变色 ${ }^{[19-20]}$ 、 光致变色 ${ }^{[21-22]}$ 、气敏元件 ${ }^{[23]}$ 、超级电容器 ${ }^{[24]}$ 等领域 均有广泛研究。 $\mathrm{MoO}_{3}$ 的晶体结构 ${ }^{[25]}$ 如图 1 所示, 由 变形八面体 $\mathrm{MoO}_{6}$ 构成的层状结构, 此结构便于小 分子或离子的嵌入和脱出, 有利于电致变色的快速 响应。同时, $\mathrm{MoO}_{3}$ 在可见光波段颜色变化柔和，更 加符合人眼对色彩的识别。 $\mathrm{MoO}_{3}$ 是一种典型的阴
极着色材料, 其电致变色过程可用以下化学方程式 表示 ${ }^{[26]}$ :

$$
\mathrm{MoO}_{3} \text { (Colorless) }+x \mathrm{~A}^{+}+x \mathrm{e}^{-} \leftrightarrow \mathrm{A}_{x} \mathrm{MoO}_{3} \text { (Blue) }
$$

其中 $0<x<1 ; \mathrm{A}^{+}$可以是 $\mathrm{Li}^{+} 、 \mathrm{Na}^{+} 、 \mathrm{H}^{+}$等。

\section{2 电致变色器件的结构与工作原理}

电致变色器件主要由基底层、透明导电(Transmittance Conducitive, TC)层、电致变色(Electrochromic, EC)层、电解质(Electrolyte, EL)层和离子存储

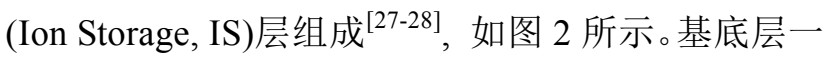
般为玻璃或柔性的聚对苯二甲酸乙二醇酯(Polyethylene Terephthalate, PET), 透明导电层一般为氟掺 杂氧化锡(Fluorine-doped Tin Oxide, FTO)或氧化铟 锡(Indium Tin Oxide, ITO)。当在 TC 层上施加电压 时, $\mathrm{EL}$ 层中的离子迁移到 $\mathrm{EC}$ 层中, 同时电子从 $\mathrm{TC}$ 层传入 $\mathrm{EC}$ 层中, 导致电致变色材料发生离子注入

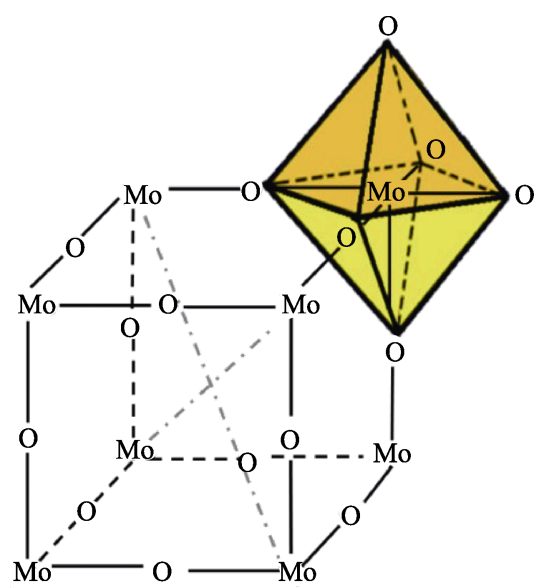

图 $1 \mathrm{MoO}_{6}$ 八面体晶胞结构图 ${ }^{[25]}$

Fig. 1 Structure diagram of $\mathrm{MoO}_{6}$ octahedral unit cell ${ }^{[25]}$

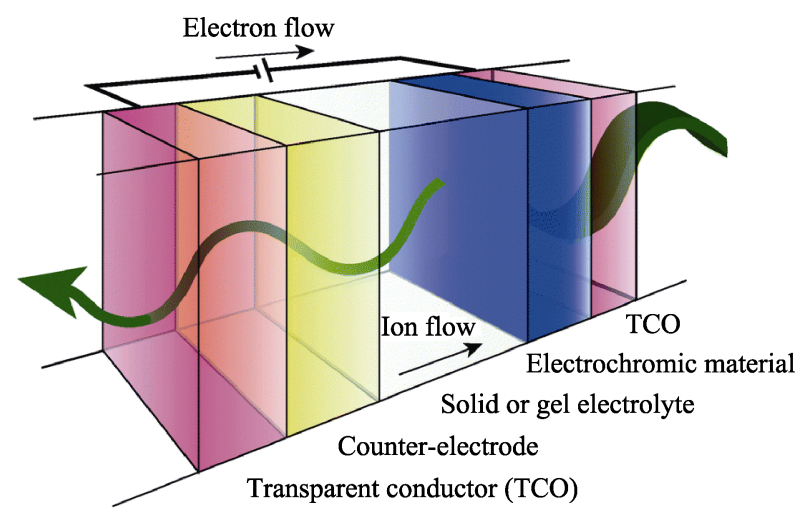

图 2 电致变色器件的结构示意图 ${ }^{[27]}$

Fig. 2 Schematic diagram of electrochromic device structure ${ }^{[27]}$ 
和氧化还原反应，出现着色(或褪色)现象。当施加反 向电压时, 已经注入 $\mathrm{EC}$ 层中的离子便会抽出, 同时 电子传回 $\mathrm{TC}$ 层而发生褪色(或着色)现象。这便是电 致变色器件工作的基本原理。

\section{3 电致变色器件的性能评价}

评价电致变色器件的性能主要考虑以下性能参 数 ${ }^{[29-30]}$ :

(1)光调制幅度: 电致变色器件在裖色态与着色 态之间的透过率之差。电致变色器件的光调制幅度 越大, 说明该器件的颜色变化越明显。

(2)响应时间：电致变色过程所花费的时间，一 般定义为着色态与褪色态之间的透过率差值达到 $90 \%$ 时所对应的时间间隔。其中, 电致变色器件从着色 态向褪色态转变的响应时间称为褪色响应时间，从 裉色态向着色态转变的响应时间称为着色响应时间。

(3)着色效率(Coloration Efficiency, CE): 单位面 积内所消耗的电荷引起的光密度的变化量。 $\mathrm{CE}=$ $\Delta \mathrm{OD} /(Q / A), \Delta \mathrm{OD}=\lg \left(T_{\mathrm{b}} / T_{\mathrm{c}}\right)$, 其中 $T_{\mathrm{b}}$ 和 $T_{\mathrm{c}}$ 分别 为电致变色器件在特定波长下褪色态和着色态的透 过率, $\Delta \mathrm{OD}$ 为光密度变化量, $Q$ 为注入的电荷, $A$ 为 电致变色器件的有效面积。

(4)循环寿命: 电致变色器件在着色态与裉色态 之间反复变色的最大次数, 当不再满足变色需求时 寿命终止。

电致变色层是电致变色器件的关键组成部分, 对电致变色器件的性能起到决定性作用。本文将对 $\mathrm{MoO}_{3}$ 电致变色薄膜的制备方法、改性研究及 $\mathrm{MoO}_{3}$ 基电致变色器件的研究进展进行综述, 并对目前存 在的问题及发展前景进行分析与展望。

\section{2 氧化钿薄膜的制备}

\section{1 气相法}

\subsection{1 化学气相沉积(CVD)}

化学气相沉积 (Chemical Vapor Deposition, $\mathrm{CVD})^{[31]}$ 是指在可通气、加热的反应器中, 利用气体 传输在固体上发生化学反应产生固态沉积物。即将 一种或多种化合物放置在反应器中, 通气, 利用气 体相互作用或在基底表面上的化学反应生成所需的 薄膜。CVD 法广泛应用于物质提纯、无机薄膜制备、 纤维涂层等方面, 其优点是沉积成膜装置简单, 可 以在各种祄底上制备元素及化合物薄膜。CVD 法 可以连续运行，不用分批处理，可以大规模制备样 品; 缺点是需要较高的温度、能量损耗大、沉积速 率低。Gesheva 等 ${ }^{[32]}$ 采用 CVD 法制备氧化钿及铇钼
氧化物薄膜, 其中铇钼氧化物具有较高的着色效率 $\left(110 \mathrm{mC} \cdot \mathrm{cm}^{-2}\right)$ 。Ivanova 等 ${ }^{[33]}$ 采用低温 CVD 方法在 150 200 ${ }^{\circ} \mathrm{C}$ 之间合成了 $\alpha-\mathrm{MoO}_{3}$ 薄膜以及 $\mathrm{MoO}_{3}-$ $\mathrm{WO}_{3}$ 薄膜, 合成的两种薄膜均具有电致变色性能, $\mathrm{MoO}_{3}-\mathrm{WO}_{3}$ 薄膜比纯金属氧化物 $\mathrm{MoO}_{3}$ 和 $\mathrm{WO}_{3}$ 薄膜 具有更大的电流密度。

\subsection{2 物理气相沉积(PVD)}

物理气相沉积(Physical Vapour Deposition, PVD) 法制备薄膜主要包括磁控溅射和真空蒸发镀膜。磁 控溅射 ${ }^{[34]}$ 是利用磁场与电场交互作用, 在真空条件 下注入氩气，惰性气体被电离后产生 $\mathrm{Ar}^{+}$轰击靶材， 通过离子的动量传递，靶上的原子、分子或离子被 溅射，在基片表面形成致密的薄膜。磁控溅射具有 沉积速度快、溅射能量低、基板温度低的优点。根 据制备条件的不同，磁控溅射既可以制备晶态薄膜 又可以制备非晶薄膜，成膜均匀性好且与基板的附 着力好。Usha 等 ${ }^{[35]}$ 以 $150 \mathrm{~W}$ 的射频功率沉积 $\mathrm{Nb}_{2} \mathrm{O}_{5}: \mathrm{MoO}_{3}$ 薄膜, 制备的薄膜具有电致变色性能, 且当 $\mathrm{Nb}_{2} \mathrm{O}_{5}: \mathrm{MoO}_{3}$ 比例为 $85: 15$ 时, 薄膜的着色效 率达到最大值 $230.3 \mathrm{~cm}^{2} \cdot \mathrm{C}^{-1}$ 。

真空蒸发镀膜法 ${ }^{[36-37]}$ 又叫热沉积法或热蒸发法, 是将原材料在真空室内加热，使材料原子或分子从 表面汽化逸出，再到达祄底表面，形成固态薄膜的 办法。用该方法制备的氧化钿薄膜的电致变色性能 与祄底温度、氧分压等因素密切相关。真空蒸发镀 膜法设备简单、操作容易，制备薄膜速度快、效率 高，薄膜生长机理简单。Miyata 等 ${ }^{\left[{ }^{[3]}\right.}$ 以纯度为 99.99\%的 $\mathrm{MoO}_{3}$ 粉末为原料, 采用热蒸发法沉积 $\mathrm{MoO}_{3}$ 薄膜, 研究了基板温度对 $\mathrm{MoO}_{3}$ 薄膜性能的影 响。结果表明, 基板温度低于 $200{ }^{\circ} \mathrm{C}$ 所形成的薄膜 具有良好的电致变色性能，而高于 $320{ }^{\circ} \mathrm{C}$ 得到的薄 膜电致变色性能较差。Dixit 等 ${ }^{[39]}$ 以纯度为 $99.97 \%$ 的 $\mathrm{MoO}_{3}$ 粉末为原料, 采用可变电阻式高真空镀膜 装置将 $\mathrm{MoO}_{3}$ 粉末用热蒸发法沉积在 ITO 上, 研究 了氧分压对 $\mathrm{MoO}_{3}$ 薄膜生长的影响, 并测试其电致 变色性能。结果表明, 在氧气分压为 $0.02 \mathrm{~Pa}$ 、基板 温度为 $150{ }^{\circ} \mathrm{C}$ 的条件下, 薄膜在 $442 \mathrm{~nm}$ 的着色效 率为 $23.98 \mathrm{~cm}^{2} \cdot \mathrm{C}^{-1}$ 。

\section{2 湿化学法}

\subsection{1 水/溶剂热法}

水/溶剂热法在物理、化学、生物、材料等多个 领域均有应用，其设备原理图与水/溶剂热制备的一 般步骤 ${ }^{[40]}$ 如图 3 所示。水/溶剂热法是指在密闭的压 力容器中, 以水/非水溶剂的溶液通过加热使得反应 物之间发生相关化学反应，从而生成特定产物的方 

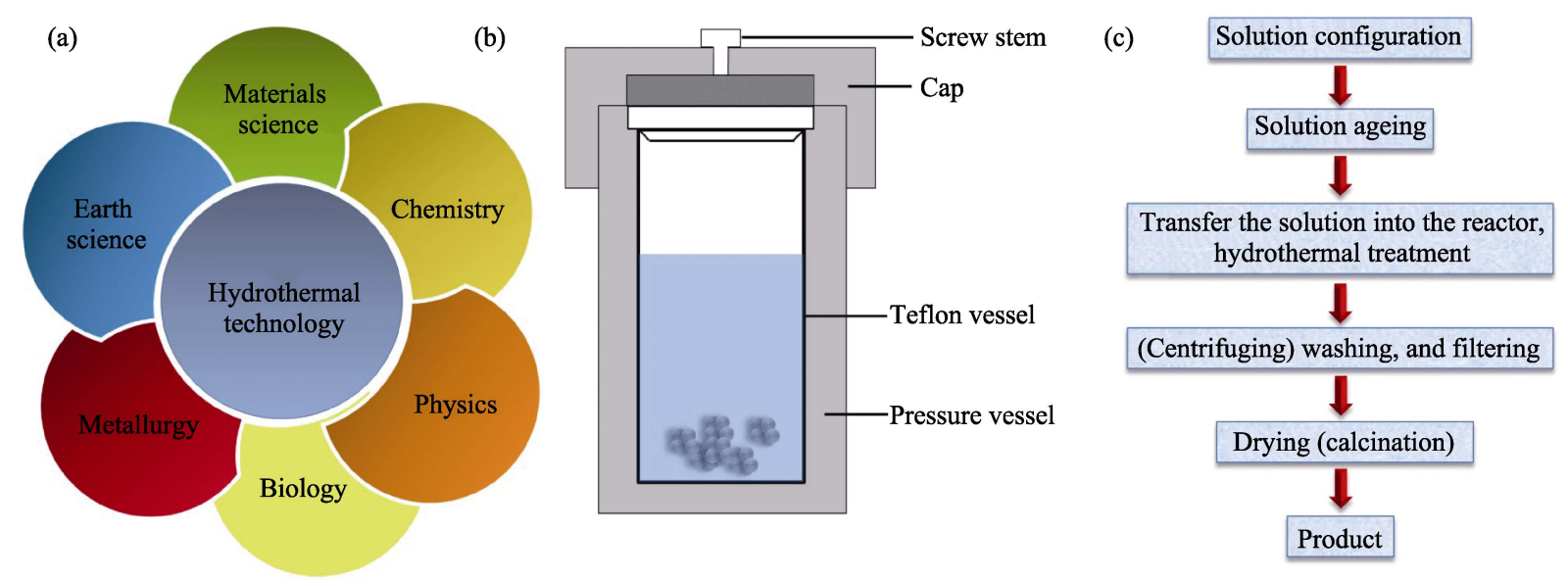

图 3 水/溶剂热法应用领域(a),水/溶剂热法设备原理图(b)和水/溶剂热制备的一般步骤(c) ${ }^{[40]}$

Fig. 3 Application field of water/solvothermal method (a), schematic diagram of water/solvothermal method equipment (b), and general steps of water/solvothermal preparation $(\mathrm{c})^{[40]}$

法 $^{[41]}$ 。通过调节水/溶剂热反应温度、反应时间、反 应物的比例等条件可以控制薄膜厚度和均匀性。水/ 溶剂热法常用于制备过渡金属氧化物 $(\mathrm{TMO})^{[42-43]}$, 其优势是操作简单, 合成的产物尺寸可控、分散性 好、成膜均匀。同时，水/溶剂热法是在无外界干扰 的密闭容器中进行, 制备的产物纯度高, 避免了环 境的污染。

姚斌等 ${ }^{[44]}$ 使用水热法合成了超长 $\mathrm{MoO}_{3}$ 纳米带, 具有良好的电化学性能。魏阳课题组 ${ }^{[45]}$ 通过水热法 制备的纳米棒和纳米颗粒两种不同形貌的 $\mathrm{MoO}_{3}$, 如 图 4 所示。从图中可以看出, 所得纳米棒(图 4(a c c)) 表面光滑, 且有部分沿着相同方向生长的纳米棒
相互组装在一起。另一种 $\mathrm{MoO}_{3}$ 产物呈颗粒状 (图 4(d f))。颗粒表面没有明显的孔隙或孔洞, 结构 致密(图 4(e))。

\subsection{2 溶胶一凝胶法}

溶胶-凝胶法 ${ }^{[46-47]}$ 是将含高化学活性组分的化 合物经过溶液、溶胶、凝胶而固化, 再经热处理形 成氧化物或其它化合物固体的方法。溶胶-凝胶法的 优点是所需设备简单、成本低，易在分子水平上控 制薄膜的组分掺杂或复合，适合大批量生产，常用 于氧化物的制备。Lemos 等 ${ }^{[26]}$ 使用溶胶-凝胶工艺 和旋涂技术制备 $\mathrm{MoO}_{3}$ 薄膜, 研究了薄膜厚度对其 电化学性能的影响, 如图 5 所示。从图 5(a)中可以看
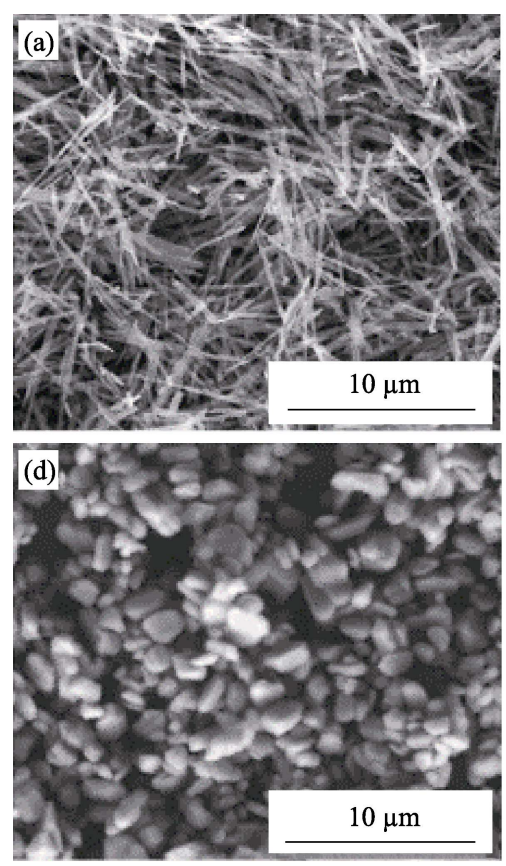
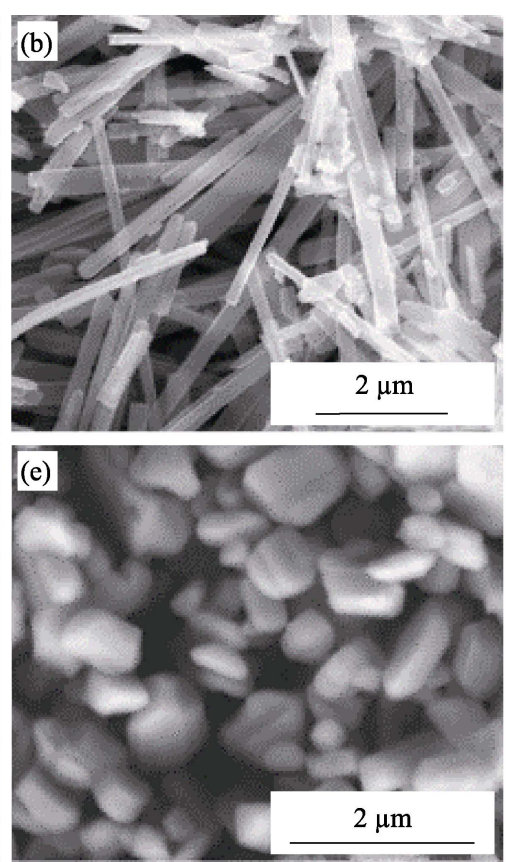
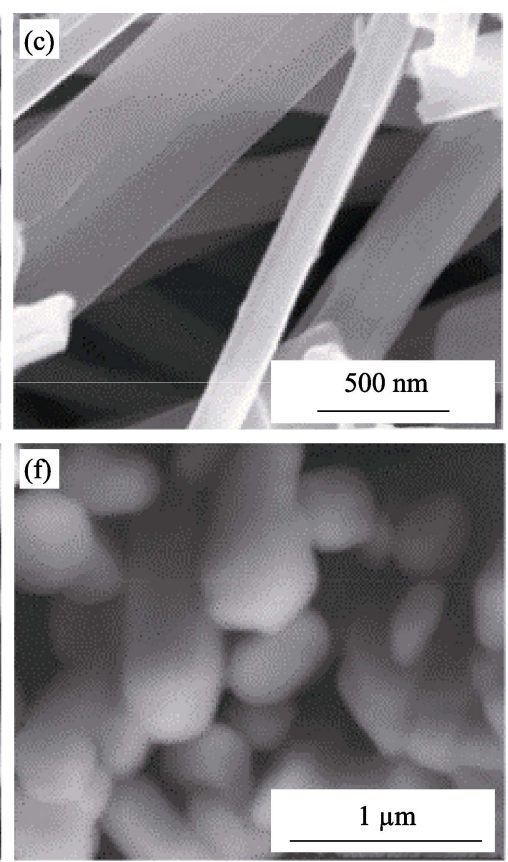

图 4 两种 $\mathrm{MoO}_{3}$ 产物在不同放大倍数下的 FESEM 照片 ${ }^{[45]}$

Fig. 4 FESEM images of two $\mathrm{MoO}_{3}$ products at different magnifications ${ }^{[45]}$

(a-c) Nanorods; (d-f) Nanoparticles 

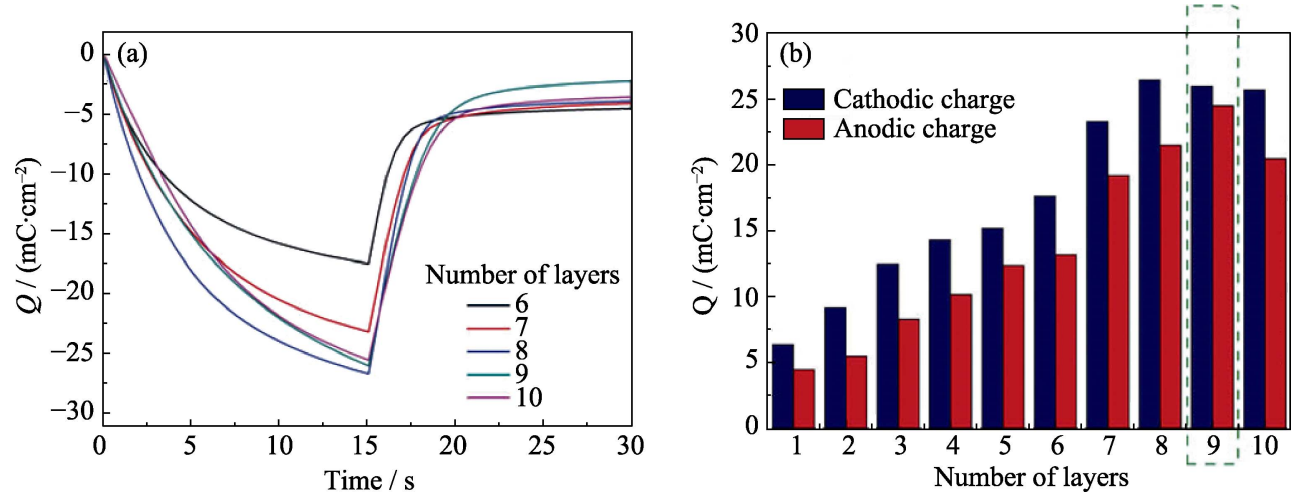

图 5 施加 $+1.5 /-1.5 \mathrm{~V}, 15 / 15 \mathrm{~s}$ 后的六至十层 $\mathrm{MoO}_{3}$ 膜的计时容量法曲线(a)和 $\mathrm{MoO}_{3}$ 薄膜层数对其电荷密度的影响(b) ${ }^{[26]}$

Fig. 5 Chronocoulometry of six- to ten-layer $\mathrm{MoO}_{3}$ film after applying $+1.5 /-1.5 \mathrm{~V}$ for $15 / 15 \mathrm{~s} \mathrm{(a)}$ and effect of the number of $\mathrm{MoO}_{3}$ thin film layers on its charge density (b) ${ }^{[26]}$

Colouful figures are available on roebsite

出电荷密度与薄膜的层数密切相关，图 5(b)表明当 $\mathrm{MoO}_{3}$ 薄膜层数为 9 时, 电化学性能和电化学过程可 逆性最佳, 其中阳极电荷 $\left(Q_{\mathrm{a}}\right)$ 和阴极电荷 $\left(Q_{\mathrm{c}}\right)$ 之比 为 0.98 。Dhanasankar 等 ${ }^{[48]}$ 采用溶胶一凝胶法制备了 铈掺杂的氧化钼薄膜, 纯氧化钼薄膜在第 25 圈和第 60 圈的阳极电流密度分别为 1.90 和 $0.65 \mathrm{~mA} \cdot \mathrm{cm}^{-2}$, 而掺杂铈的氧化钿薄膜在第 25 圈和第 130 圈的阳极 电流密度分别为 2.80 和 $1.37 \mathrm{~mA} \cdot \mathrm{cm}^{-2}$ 。由此可见, 铈掺杂增强了氧化钼薄膜的电致变色性能, 并使其 循环稳定性也得到了改善。

\subsection{3 电化学沉积法}

电化学沉积法 ${ }^{[49]}$ 是在含有电解质的电解池中, 以情性电极为阴极, 在外加电压下发生氧化还原反 应, 将电解池中的离子沉积在电极基底表面形成 薄膜的方法。电化学沉积制备薄膜与电解液的组 成、 $\mathrm{pH}$ 、温度等条件有关, 其优点包括可精准控制 沉积厚度和沉积速度, 同时可以在异形结构件上沉 积薄膜, 反应温度低, 成本低。温洋洋等 ${ }^{[50]}$ 采用电 化学沉积制备了氧化钼包覆碳纳米管复合纤维 $\left(\mathrm{MoO}_{x} / \mathrm{CNT}\right)$, 该复合纤维具有明显的电化学活性, 电容量为 $19 \mathrm{~F} \cdot \mathrm{g}^{-1}$, 可用于电化学超级电容器的柔 性电极。Zhuzhel'skii 等 ${ }^{[51]}$ 首先通过恒电流法, 在玻 璃碳(Glass Carbon, GC) 电极表面沉积了导电聚合物 (PEDOT) 薄膜, 然后以 $0.2 \mathrm{~mol} / \mathrm{L}$ 钼酸锂为电解液, 分别在 $\mathrm{GC}$ 和 $\mathrm{GC} / \mathrm{PEDOT}$ 电极上沉积了氧化钿薄膜, 制备的薄膜表面光滑、厚度均匀。

\section{3 喷雾热解法}

喷雾热解法 ${ }^{[52-53]}$ 是通过金属前驱体的热分解来 制备半导体氧化物和硫化物及金属纳米颗粒的方 法。此方法制备的样品分散性好、纯度高、粒度均 匀。Cho 等 ${ }^{[54]}$ 通过一步喷雾热解法将 $\mathrm{MoO}_{3}$ 均匀分 布在非晶态碳基体中。图 6 为反应装置示意图, 用
超声波喷雾发生器产生 $\mathrm{MoO}_{3}$ 液滴, 通过 $\mathrm{N}_{2}$ 的流动 将其带到石英管反应器, 在热壁反应器内经过干 燥、分解和结晶, $\mathrm{MoO}_{3}$ 液滴在 $6 \mathrm{~s}$ 内直接形成平均 直径为 $0.7 \mu \mathrm{m}$ 的碳复合微球, 复合薄膜在经过 100 次循环后仍然有 $811 \mathrm{mAh} \cdot \mathrm{g}^{-1}$ 的高比放电容量。 Mousavi-zadeh 等 ${ }^{[55]}$ 在 $450{ }^{\circ} \mathrm{C}$ 的衬底温度下, 用喷 雾热解法制备出未掺杂和 $\mathrm{Zn}$ 掺杂的 $\mathrm{MoO}_{3}$ 薄膜, 并 对其微观结构、形貌及光学性能进行了研究, 结果 表明 $\mathrm{Zn}$ 的掺杂量增大至 $5 \mathrm{at} \%$ 时, $\mathrm{MoO}_{3}$ 晶粒尺寸减 小至约 $60 \mathrm{~nm}$, 薄膜的带隙增加; 随着 $\mathrm{Zn}$ 掺杂量的 增加，吸收光谱发生蓝移。

\section{4 其它方法}

除上述常用方法，研究者们还在积极寻找新的 合成氧化钿薄膜方法。于海燕等 ${ }^{[56]}$ 将水热法与电沉 积法结合在 FTO 上制备出钼钛复合纳米薄膜，复合 薄膜的多孔结构便于离子扩散, 提高了电致变色性

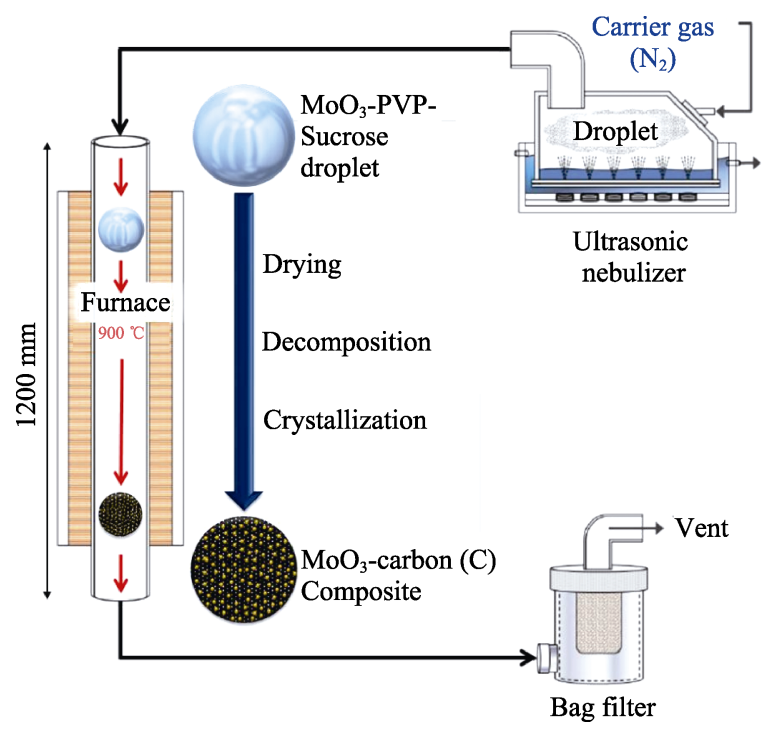

图 6 喷雾热解系统用于制备 $\mathrm{MoO}_{3} / \mathrm{C}$ 复合微球的示意图 ${ }^{[54]}$

Fig. 6 Schematic diagram of spray pyrolysis system applied in the preparation of $\mathrm{MoO}_{3} / \mathrm{C}$ composite microspheres ${ }^{[54]}$ 
能。Martín-Ramos 等 ${ }^{[57]}$ 提出了一种通过层状 $\mathrm{MoS}_{2} / \mathrm{g}$ $\mathrm{C}_{3} \mathrm{~N}_{4}$ 纳米杂化退火获得多层堆叠结构的 $\alpha-\mathrm{MoO}_{3}$ 晶 体。首先, 通过钼酸盐、柠檬酸盐和硫脲反应获得 $\mathrm{MoS}_{2}$, 然后将 $n\left(\mathrm{~g}-\mathrm{C}_{3} \mathrm{~N}_{4}\right): n\left(\mathrm{MoS}_{2}\right)=1: 1$ 混合, 分散 在碳酸亚丙酯中, 经过超声、离心、沉淀, $150{ }^{\circ} \mathrm{C}$ 干 燥 $24 \mathrm{~h}$, 得到 $\mathrm{MoS}_{2} / \mathrm{g}-\mathrm{C}_{3} \mathrm{~N}_{4}$ 复合材料; $650{ }^{\circ} \mathrm{C}$ 下煅烧, 得到无色(或绿色) $\alpha-\mathrm{MoO}_{3}$ 多层堆叠结构的纳米板。 如图 7 所示, $\mathrm{SEM}$ 照片显示了 $\alpha-\mathrm{MoO}_{3}$ 多层堆叠的结 构, 但与工业煅烧 $\mathrm{MoO}_{3} \cdot \mathrm{H}_{2} \mathrm{O}$ 获得的 $\mathrm{MoO}_{3}$ 形貌不 同(图 7(d))。此种方法与 PVD 和 CVD 方法相比, 结 晶度提高, 并克服了在能量需求和设备以及常规液 相合成技术方面的某些局限性。

\section{3 氧化钼的改性}

$\mathrm{MoO}_{3}$ 薄膜虽然具有变色响应时间短的优点, 但存在着色效率低、与基底结合不牢固等缺点。为 此, 研究人员通过向氧化钼中掺杂离子以改变氧化 钼的结构, 从而提高 $\mathrm{MoO}_{3}$ 薄膜的电致变色性能。

\section{1 单一离子掺杂 $\mathrm{MoO}_{3}$}

掺入离子可提高 $\mathrm{MoO}_{3}$ 薄膜中电荷的注入量, 使得掺杂后的薄膜具有良好的可逆性能。章俞之 等 $^{[58]}$ 室温下采用溶胶-凝胶法制备了 $10 \mathrm{~mol} \% \mathrm{Li}^{+}$掺
杂的 $\mathrm{MoO}_{3}$ 薄膜, 该薄膜具有良好的电致变色性能。 与未掺杂的 $\mathrm{MoO}_{3}$ 薄膜相比, $\mathrm{Li}^{+}$掺杂 $\mathrm{MoO}_{3}$ 薄膜的 光调制幅度为 $32.3 \%$ 。 Mahajan 等 ${ }^{[59]}$ 使用喷雾热解 技术制备了 $\mathrm{Ti}$ 掺杂的 $\mathrm{MoO}_{3}$ 薄膜，随着 $\mathrm{Ti}$ 掺杂浓度 的增加, $\mathrm{MoO}_{3}$ 薄膜逐渐由多晶态转变为无定形态, 且颗粒尺寸逐渐减小。当 $\mathrm{Ti}$ 掺杂浓度为 $9 \mathrm{at} \%$ 时，制 备薄膜呈无定形海绵状，这种结构有利于离子的嵌 入和脱嵌，具有良好的电致变色性能。Layegh 等 ${ }^{[60]}$ 以七水合七钼酸铵和氯化铁作为前驱体，通过溶 胶一凝胶法分别制备了未掺杂和铁掺杂的氧化钼薄 膜。与纯氧化钼电极相比, 提高铁掺杂浓度会显著 增强薄膜的电化学性能。掺杂可以改变主体氧化物 的形态和结构, 同时还可以改善其低电子电导率的 问题。

\section{$3.2 \mathrm{Fe} 、 \mathrm{Co}$ 共掺杂 $\mathrm{MoO}_{3}$}

Kamoun 等 ${ }^{[61]}$ 利用喷雾热解制备了板状的纳米 $\mathrm{MoO}_{3}$ 薄膜, 再使用喷雾热解法掺杂 $\mathrm{Fe} 、 \mathrm{Co}$, 得到 $\mathrm{Fe} 、 \mathrm{Co}$ 共掺杂的 $\mathrm{MoO}_{3}$ 薄膜, 研究了 $\mathrm{Fe} 、 \mathrm{Co}$ 共掺 杂对 $\mathrm{MoO}_{3}$ 薄膜光学性能的影响, 如图 8 所示。结 果表明: 在可见光范围内, 薄膜的平均透过率在 $40 \% \sim 75 \%$, 反射率在 $7 \% \sim 37 \%$, 薄膜的吸收边随掺 杂浓度而变化，其中 $\mathrm{MoO}_{3}: \mathrm{Fe} 2 \%-\mathrm{Co} 1 \%$ 样品在可 见光范围内的透过率最高。
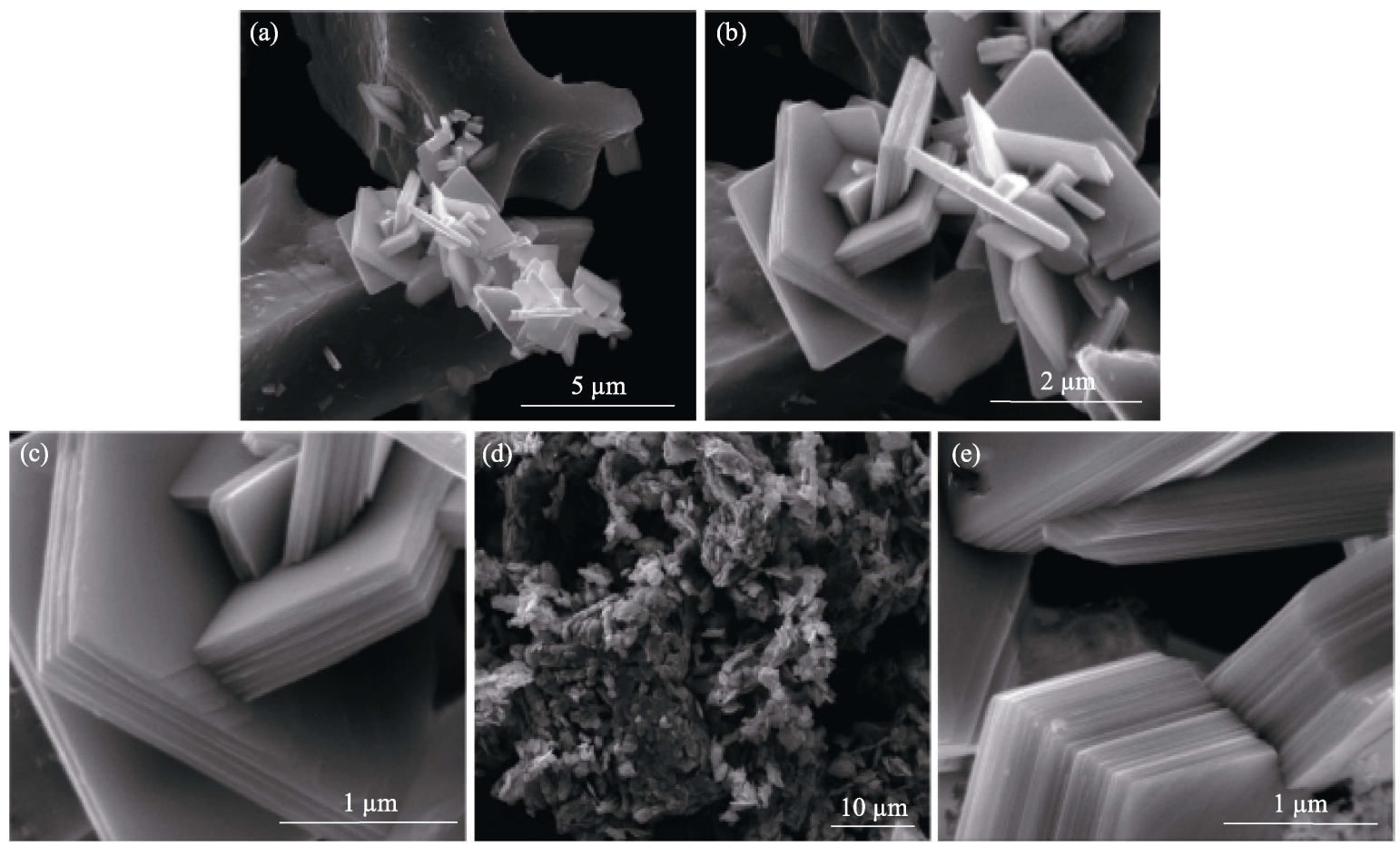

图 7 具有多层堆叠结构的 $\alpha-\mathrm{MoO}_{3}$ 晶体在不同放大倍率下的 SEM 显微照片 $(\mathrm{a} \sim \mathrm{c})$, 通过衫烧市售钼酸 $\left(\mathrm{MoO}_{3} \cdot \mathrm{H}_{2} \mathrm{O}\right)$ 获得的 $\mathrm{MoO}_{3}$ 晶体的 SEM 照片(d), 以及具有 44 层堆积的 $\alpha-\mathrm{MoO}_{3}$ 的 SEM 显微照片(e) ${ }^{[57]}$

Fig. 7 SEM images of $\alpha-\mathrm{MoO}_{3}$ crystals with a multi-layer stack structure at different magnifications (a-c), SEM image of $\mathrm{MoO}_{3}$ crystals obtained by calcination of commercial molybdic acid $\left(\mathrm{MoO}_{3} \cdot \mathrm{H}_{2} \mathrm{O}\right)(\mathrm{d})$, and SEM image of $\alpha-\mathrm{MoO}_{3}$ stacking with 44 layers (e) ${ }^{[57]}$ 


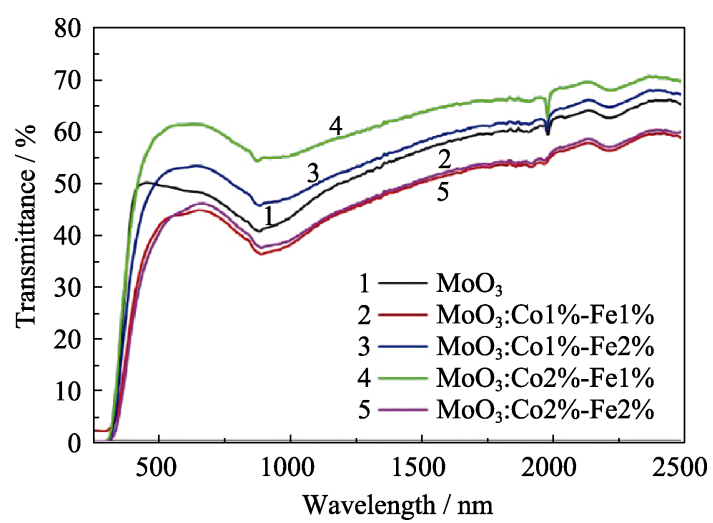

图 8 未掺杂与掺杂 $\mathrm{Fe}-\mathrm{Co}$ 的 $\mathrm{MoO}_{3}$ 薄膜的透射光谱 ${ }^{[61]}$

Fig. 8 Transmission spectra of undoped and Fe-Co-doped $\mathrm{MoO}_{3}$ films ${ }^{[61]}$

\section{4 氧化锄电致变色器件}

随着电致变色技术的发展, 尤其是近年来电致 变色技术在手机上的应用，电致变色领域成为人们 关注的焦点。单一 $\mathrm{MoO}_{3}$ 电致变色器件的制备依然 是研究重点。王金敏课题组用两种不同方法制备了 $\mathrm{MoO}_{3}$ 薄膜, 并组装了电致变色器件。一种方法是 以 $\mathrm{MoS}_{2}$ 为钼源, 采用超声波辅助剥离 $\mathrm{MoS}_{2}$, 将其 分散到乙醇溶液中，再旋涂到 ITO 透明导电玻璃 上，经过炦烧得到 $\mathrm{MoO}_{3}$ 薄膜 ${ }^{[62]}$ 。由制备的 $\mathrm{MoO}_{3}$ 薄膜组装成的电致变色器件在 $580 \mathrm{~nm}$ 处的透过率 调制幅度为 $16.2 \%$, 着色响应时间为 $3.0 \mathrm{~s}$, 褪色响 应时间为 $9.0 \mathrm{~s}$ 。另一种方法是以钿粉为钼源, 通过 水热法在 FTO 透明导电玻璃上直接生长 $\mathrm{MoO}_{3}$ 薄 膜 ${ }^{[63]}$ 。组装的电致变色器件在 $750 \mathrm{~nm}$ 处的透过率 调制幅度为 $13.3 \%$, 着色与褪色响应时间分别为 3.5 和 $2.9 \mathrm{~s}$ 。

由单一氧化钼薄膜制备的电致变色器件虽然可 以变色, 但是光调制幅度较小、着色效率不高, 因
此复合电致变色器件应运而生。氧化钼电致变色器 件存在颜色变化单一、响应速度慢等缺陷。将氧化 钼薄膜与其它电致变色薄膜组成复合变色器件可 以改善这些缺陷, 使器件具有更好的电致变色性 能 ${ }^{[64]}$ 。

张阁等 ${ }^{[65]}$ 先用水热法制备出六方相氧化钼 $\left(h-\mathrm{MoO}_{3}\right)$, 烘干得到 $\mathrm{MoO}_{3}$ 样品，与乙基纤维素、无 水乙醇、松油醇充分搅拌直至无水乙醇挥发, 得到 $\mathrm{MoO}_{3}$ 浆料, 旋涂在 ITO 表面, 加热, 制备得到氧化 钼薄膜, 再用恒电压聚合法在 ITO 上制得聚吡咯薄膜, 将两者组装成纳米氧化钼/聚吡咯复合变色器件。测 试结果表明, 随着电压的升高 $(-1.5 \mathrm{~V} \rightarrow+1.5 \mathrm{~V})$, 薄 膜在 $481 \mathrm{~nm}$ 处吸收峰的强度减弱, 光学对比度变化 较大，强度从 0.62 减小到 0.55 ; 着色时间为 $35 \mathrm{~s}$, 褪 色时间为 $22 \mathrm{~s}$; 着色态颜色为浅蓝色, 褪色态颜色 为淡黄色。

由于过渡金属氧化物电致变色器件电导率较 差、电荷传输势垒较高。为改善这些缺点, 李海增 等 ${ }^{[66]}$ 引入共轭聚合物聚乙撑二氧噻吩-聚苯乙烯磺 酸盐(PEDOT:PSS)制备得到有机-无机纳米复合薄膜。 使用逐层喷涂沉积技术分别制备 $\mathrm{W}_{0.71} \mathrm{Mo}_{0.29} \mathrm{O}_{3}$ 薄 膜、 $\mathrm{W}_{0.71} \mathrm{Mo}_{0.29} \mathrm{O}_{3} /$ PEDOT:PSS 薄膜、PEDOT:PSS 薄膜。研究结果表明纳米复合电极的光学对比度优 于纯 PEDOT:PSS 和 $\mathrm{W}_{0.71} \mathrm{Mo}_{0.29} \mathrm{O}_{3}$ 电极, 比纯薄膜 组合的线性预测对比度高 $23 \%$ 。图 9(a)动力学特征 曲线表明，以透过率变化 90\%所需的时间定义为切 换时间, PEDOT:PSS 着色时间和褪色时间分别为 6.5 和 $3 \mathrm{~s}$ 。相同条件下纯 $\mathrm{W}_{0.71} \mathrm{Mo}_{0.29} \mathrm{O}_{3}$ 电极着色时间为 $22.1 \mathrm{~s}$, 褪色时间为 $13.9 \mathrm{~s}$ 。而在 $\mathrm{W}_{0.71} \mathrm{Mo}_{0.29} \mathrm{O}_{3}$ 电极中 引入 PEDOT:PSS 可使响应时间缩短 20\% (着色时间 $17.9 \mathrm{~s}$, 褪色时间 $10.5 \mathrm{~s})$ 。从图 9(b)电极的着色效率 曲线看出 $\mathrm{W}_{0.71} \mathrm{Mo}_{0.29} \mathrm{O}_{3} / \mathrm{PEDOT}: \mathrm{PSS}$ 电极的着色效 率为 $52.8 \mathrm{~cm}^{2} \cdot \mathrm{C}^{-1}$, 是 $\mathrm{W}_{0.71} \mathrm{Mo}_{0.29} \mathrm{O}_{3}$ 电极 $21.7 \mathrm{~cm}^{2} \cdot \mathrm{C}^{-1}$
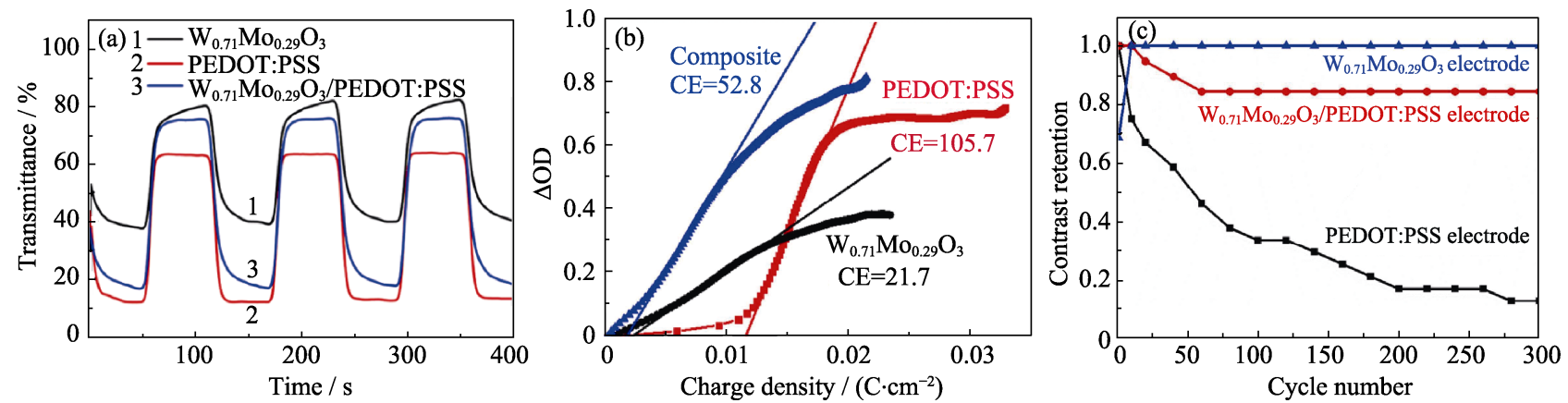

图 $9 \mathrm{~W}_{0.71} \mathrm{Mo}_{0.29} \mathrm{O}_{3}$ 薄膜、PEDOT:PSS 薄膜和 $\mathrm{W}_{0.71} \mathrm{Mo}_{0.29} \mathrm{O}_{3} /$ PEDOT:PSS 薄膜 $632.8 \mathrm{~nm}$ 下的 原位动力学特征曲线(a), 电极的着色效率曲线(b)和循环稳定性曲线(c) ${ }^{[66]}$

Fig. 9 In-situ kinetic properties measured at $632.8 \mathrm{~nm}$ for $\mathrm{W}_{0.71} \mathrm{Mo}_{0.29} \mathrm{O}_{3}$ film, PEDOT:PSS film and $\mathrm{W}_{0.71} \mathrm{Mo}_{0.29} \mathrm{O}_{3} /$ PEDOT:PSS film (a), coloration efficiencies (b), and cycling stabilities (c) of the electrodes ${ }^{[66]}$ 
的两倍。图 9(c)为电极的循环稳定性曲线, 从图中 可以看出 $\mathrm{W}_{0.71} \mathrm{Mo}_{0.29} \mathrm{O}_{3} /$ PEDOT:PSS 电极在 300 个 循环后的对比度保持率为 $84.2 \%$ 。

除了制备复合电致变色器件外, 一种既变色又 储能的电致变色器件引起了人们的注意, 这种器件 即双功能电致变色器件 ${ }^{[67]}$ 。这类器件的电致变色材 料从最初的普鲁士蓝(Prussian Blue, $\mathrm{PB})^{[68]}$, 发展到 $\mathrm{WO}_{3}{ }^{[69]}$ 、铇钼复合氧化物 ${ }^{[70]}$ 、聚吡咯 ${ }^{[71]}$ 等。李海增 等 ${ }^{[70]}$ 通过一种自上而下的方法将 Mo 粉添加到
$\mathrm{HNO}_{3}$ 溶液中, 搅拌、回流形成白色悬浮液, 离心、 洗涤后将白色产物分散在去离子水中形成前驱体溶 液, 制备得到 $\mathrm{MoO}_{3}$ 胶体。再通过湿化学法将高度 分散的 $\mathrm{MoO}_{3}$ 胶体嵌入 $\mathrm{W}_{0.71} \mathrm{Mo}_{0.29} \mathrm{O}_{3}$ 中, 形成 $\mathrm{MoO}_{3}-\mathrm{W}_{0.71} \mathrm{Mo}_{0.29} \mathrm{O}_{3}$ 纳米复合材料, 经喷涂再得到 $\mathrm{MoO}_{3}-\mathrm{W}_{0.71} \mathrm{Mo}_{0.29} \mathrm{O}_{3}$ 复合薄膜。以此为工作电极与 喷涂的 $\mathrm{NiO}$ 对电极组装成互补型储能智能窗器件, 如图 10 所示。互补型电致变色电池在 $-2.5 \mathrm{~V}$ 下着色 $1 \mathrm{~min}$, 可为 LED 供电 $10 \mathrm{~min}$ 。
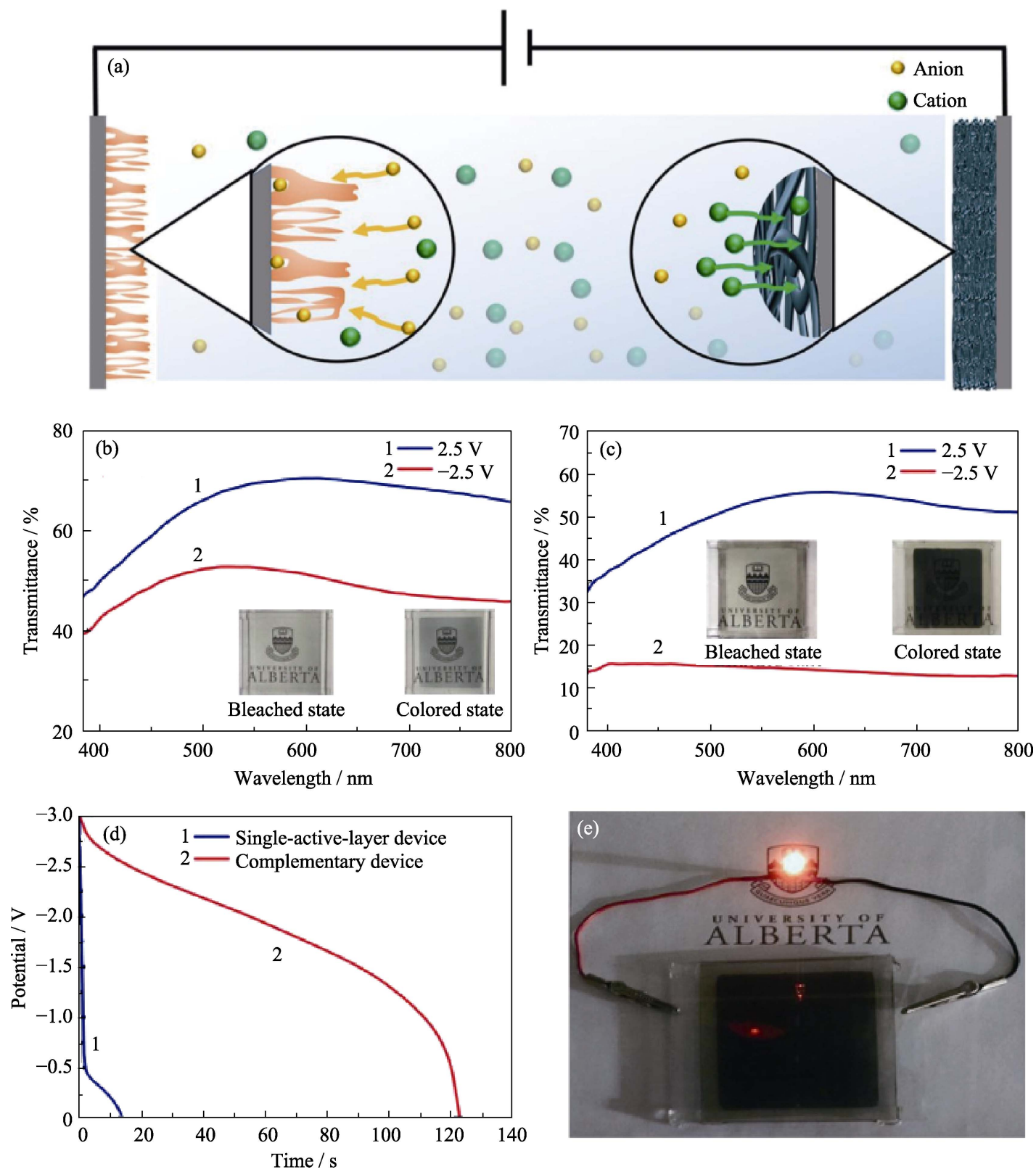

图 10 互补型电致变色电池的示意图(a), 单活性层电致变色电池(b)和互补型电致变色电池的 可见-近红外透射光谱(c), 单层器件和互补型器件的放电曲线(电流密度为 $0.05 \mathrm{~mA} \cdot \mathrm{cm}^{-2}$ ) (d),

以及互补型电致变色电池在 $-2.5 \mathrm{~V}$ 着色后可以使 LED 点亮 $10 \mathrm{~min}$ 以上(e $)^{[70]}$

Fig. 10 Schematic diagram of a complementary electrochromic battery (a), visible-near-infrared transmission spectra of single active layer electrochromic battery (b) and complementary electrochromic batteries (c), discharge curves (current density is $0.05 \mathrm{~mA} \cdot \mathrm{cm}^{-2}$ ) of single-layer device and complementary device (d), and complementary electrochromic batteries lighting up the LED for $10 \mathrm{~min}$ after being colored at $-2.5 \mathrm{~V}(\mathrm{e})^{[70]}$ 


\section{5 结束语}

近年来, $\mathrm{MoO}_{3}$ 电致变色材料在响应时间和着 色态特点方面的优势, 使得 $\mathrm{MoO}_{3}$ 在电致变色材 料方面的研究愈发丰富。但是 $\mathrm{MoO}_{3}$ 电致变色薄 膜着色效率较低、与基底附着不牢固，使得 $\mathrm{MoO}_{3}$ 电致变色器件的使用寿命较短。为提高其电致变 色性能, 研究人员探索出三条改进路线: 1) 在已 有制备方法的基础上, 不断探索新的 $\mathrm{MoO}_{3}$ 薄膜 的制备方法, 或者采用两种已有的不同方法制备 $\mathrm{MoO}_{3}$ 薄膜; 2) 对 $\mathrm{MoO}_{3}$ 进行掺杂, 不同的掺杂离子 会产生不同的形貌结构, 对应的电致变色性能也会 受到不同程度的影响, 因此研究不同离子掺杂对 $\mathrm{MoO}_{3}$ 电致变色性能的影响是一个重要方向；3）与 其它有机或无机电致变色材料组装成互补型电致变 色器件。目前关于 $\mathrm{MoO}_{3}$ 的互补型电致变色器件研 究较少, 互补型电致变色器件不仅有良好的电致变 色性能, 而且可以呈现出更加丰富的颜色变化, 拓 展了 $\mathrm{MoO}_{3}$ 电致变色材料的实际应用范围。目前 $\mathrm{MoO}_{3}$ 电致变色材料还没有得到广泛应用, 今后可 借鉴以上思路来丰富 $\mathrm{MoO}_{3}$ 电致变色材料与器件的 研究方向, 以获得性能优异的大面积电致变色器件, 使得 $\mathrm{MoO}_{3}$ 电致变色材料的应用更为广泛。

\section{参考文献:}

[1] WANG S Z, CAI S W, CAI W A, et al. Organic-inorganic hybrid electrochromic materials, polysilsesquioxanes containing triarylamine, changing color from colorless to blue. Scientific Reports, 2017, 7(1): 14627.

[2] WANG Z, WANG X Y, CONG S, et al. Towards full-colour tunability of inorganic electrochromic devices using ultracompact FabryPerot nanocavities. Nature Communications, 2020, 11(1): 302.

[3] WANG Z, WANG X, CONG S, et al. Fusing electrochromic technology with other advanced technologies: a new roadmap for future development. Materials Science and Engineering: R: Reports, 2020, 140: 100524

[4] HASANI A, LE Q V, NGUYEN T P, et al. Facile solution synthesis of tungsten trioxide doped with nanocrystalline molybdenum trioxide for electrochromic devices. Scientific Reports, 2017, 7(1): 13258.

[5] LIN Y S, TSAI T H, HUNG S C, et al. Enhanced lithium electrochromism of atmospheric pressure plasma jet-synthesized tungsten/ molybdenum oxide films for flexible electrochromic devices. Journal of Solid State Electrochemistry, 2013, 17(4): 1077-1088.

[6] BECHINGER C, FERRERE S, ZABAN A, et al. Photoelectrochromic windows and displays. Nature, 1996, 383(6601): 608-610

[7] XIONG K, EMILSSON G, MAZIZ A, et al. Plasmonic metasufaces with conjugated polymers for flexible electronic paper in color. Advanced Materials, 2016, 28(45): 9956-9960.

[8] WANG J M, YU H Y, MA D Y. Progress in the preparation and application of nanostructured manganese dioxide. Journal of Inorganic Materials, 2020, 35(12): 1307-1314.

[9] CHANG C C, CHI P W, CHANDAN P, et al. Electrochemistry and rapid electrochromism control of $\mathrm{MoO}_{3} / \mathrm{V}_{2} \mathrm{O}_{5}$ hybrid nanobilayers. Materials, 2019, 12(15): 2475.
[10] XU T, WALTER E C, AGRAWAL A, et al. High-contrast and fast electrochromic switching enabled by plasmonics. Nature Communications, 2016, 7(1): 10479.

[11] PLATT J R. Electrochromism, a possible change of color producible in dyes by an electric field. The Journal of Chemical Physics, 1961, 34(3): 862-863.

[12] SUI Q, REN X T, DAI Y X, et al. Piezochromism and hydrochromism through electron transfer: new stories for viologen materials. Chemical Science, 2017, 8(4): 2758-2768.

[13] YU W H, ZHANG Y, KANG E T, et al. Electroless metallization of dielectric SiLK surfaces functionalized by viologen. Journal of The Electrochemical Society, 2003, 150(8): F156-F163.

[14] MI S, WU J C, LIU J, et al. AIEE-active and electrochromic bifunctional polymer and device composed thereof synchronously achieving electrochemical fluorescence switching and electrochromic switching. ACS Applied Materials \& Interfaces, 2015, 7(49): 27511-27517.

[15] CHEN X M, LIU H L, XU Z P, et al. Highly regiosymmetric homopolymer based on dioxythiophene for realizing waterprocessable blue-to-transmissive electrochrome. ACS Applied Materials \& Interfaces, 2015, 7(21): 11387-11392.

[16] DEB S K. A novel electrophotographic system. Applied Optics, 1969, 8(Suppl 1): 192-195.

[17] ATINAFU D G, DONG W, DU M. Controllable synthesis and surface modification of molybdenum oxide nanowires: a short review. Tungsten, 2019, 1(4): 258-265.

[18] HE Y C, LI T Z, ZHONG X L, et al. Lattice and electronic structure variations in critical lithium doped nickel oxide thin film for superior anode electrochromism. Electrochimica Acta, 2019, 316: $143-151$

[19] BULJA S, KOPF R, NOLAN K, et al. Tuneable dielectric and optical characteristics of tailor-made inorganic electro-chromic materials. Scientific Reports, 2017, 7(1): 13484.

[20] MA Y, ZHANG X, YANG M, et al. Controlled growth of $\mathrm{MoO}_{3}$ nanorods on transparent conducting substrates. Materials Letters, 2014, 136: 146-149.

[21] ZHUO Q Q, TANG J J, SUN J, et al. High efficient reduction of graphene oxide via nascent hydrogen at room temperature. Materials, 2018, 11(3): 340.

[22] LI Y B, BANDO Y, GOLBERG D, et al. Field emission from $\mathrm{MoO}_{3}$ nanobelts. Applied Physics Letters, 2002, 81(26): 5048.

[23] CHOI H, HEO J H, HA S, et al. Facile scalable synthesis of $\mathrm{MoO}_{2}$ nanoparticles by new solvothermal cracking process and their application to hole transporting layer for $\mathrm{CH}_{3} \mathrm{NH}_{3} \mathrm{PbI}_{3}$ planar perovskite solar cells. Chemical Engineering Journal, 2017, 310: 179-186.

[24] TAO T, CHEN Q Y, HU H P, et al. $\mathrm{MoO}_{3}$ nanoparticles distributed uniformly in carbon matrix for supercapacitor applications. Materials Letters, 2011, 66(1): 102-105.

[25] ZENG L, CHENG C Y. A literature review of the recovery of molybdenum and vanadium from spent hydrodesulphurisation catalysts. Hydrometallurgy, 2009, 98(1): 1-9.

[26] LEMOS R M J, ALCÁZAR J C B, CARREÑO N L V, et al. Influence of molybdenum trioxide thin film thickness on its electrochemical properties. Molecular Crystals and Liquid Crystals, 2017, 655(1): 40-50.

[27] YANG P H, SUN P, MAI W J. Electrochromic energy storage devices. Materials Today, 2016, 19(7): 394-402.

[28] ZHANG X, LI W J, LI Y, et al. Research progress of inorganic all-solid-state electrochromic devices. Materials Science and Technology, 2020, 28(3): 140-149.

[29] MORTIMER R J, ROSSEINSKY D R, MONK P M S. Electrochromic Materials and Devices. Germany: Wiley-VCH Verlag GmbH \& Co. KGaA, 2015: 1-638.

[30] JIA H X, CAO X, JIN P S. Advances in inorganic all-solid-state electrochromic materials and devices. Journal of Inorganic Materials, 2020, 35(5): 511-524.

[31] ZHAO X H, WEI C, GAI Z Q, et al. Chemical vapor deposition and its application in surface modification of nanoparticles. Chemical Papers, 2020, 74(3): 767-778. 
[32] GESHEVA K A, CZIRAKI A, IVANOVA T, et al. Crystallization of chemically vapor deposited molybdenum and mixed tungsten/ molybdenum oxide films for electrochromic application. Thin Solid Films, 2007, 515(11): 4609-4613.

[33] IVANOVA T, GESHEVA K A, POPKIROV G, et al. Electrochromic properties of atmospheric CVD $\mathrm{MoO}_{3}$ and $\mathrm{MoO}_{3}-\mathrm{WO}_{3}$ films and their application in electrochromic devices. Materials Science \& Engineering $B, 2005$, 119(3): 232-239.

[34] ARROYO-HERNÁNDEZ M, ÁlVARO R, SERRANO S, et al. Catalytic growth of $\mathrm{ZnO}$ nanostructures by r.f. magnetron sputtering. Nanoscale Research Letters, 2011, 6: 437.

[35] USHA N, SIVAKUMAR R, SANJEEVIRAJA C. Structural, optical and electrochromic properties of $\mathrm{Nb}_{2} \mathrm{O}_{5}: \mathrm{MoO}_{3}$ (95:5, 90:10, and $85: 15)$ thin films prepared by RF magnetron sputtering technique. Materials Letters, 2018, 229(15): 189-192.

[36] ALVARADO J A, MALDONADO A, JUAREZ H, et al. Characterization of nanostructured $\mathrm{ZnO}$ thin films deposited through vacuum evaporation. Beilstein Journal of Nanotechnology, 2015, 6: 971-975.

[37] VARNAMKHASTI M G, FALLAH H R, ZADSAR M. Effect of heat treatment on characteristics of nanocrystalline $\mathrm{ZnO}$ films by electron beam evaporation. Vacuum, 2012, 86(7): 871-875.

[38] MIYATA N, SUZUKI T, OHYAMA R. Physical properties of evaporated molybdenum oxide films. Thin Solid Films, 1996, 281: 218-222.

[39] DIXIT D, MADHURI K V. Effect of oxygen partial pressure on the growth of molybdenum trioxide thin films. Materials Today: Proceedings, 2019, 19: 2688-2692.

[40] YANG G J, PARK S J. Conventional and microwave hydrothermal synthesis and application of functional materials: a review. Materials, 2019, 12(7): 1177

[41] QURESHI N, ARBUJ S, SHINDE M, et al. Swift tuning from spherical molybdenum microspheres to hierarchical molybdenum disulfide nanostructures by switching from solvothermal to hydrothermal synthesis route. Nano Convergence, 2017, 4(1): 25.

[42] SHI E W, XIA C T, WANG B G, et al. Development application and of hydrothermal method. Journal of Inorganic Materials, 1996, 11(2): 193-206.

[43] ZHOU E, TIAN L L, CHENG Z F, et al. Design of NiO flakes@, $\mathrm{CoMoO}_{4}$ nanosheets core-shell architecture on Ni foam for highperformance supercapacitors. Nanoscale Research Letters, 2019, 14: 221.

[44] YAO B, HUANG L, ZHANG J, et al. Flexible transparent molybdenum trioxide nanopaper for energy storage. Advanced Materials, 2016, 28(30): 6353-6358.

[45] HE S H, LI W D, FENG L, et al. Rational interaction between the aimed gas and oxide surfaces enabling high-performance sensor: the case of acidic $\alpha-\mathrm{MoO}_{3}$ nanorods for selective detection of triethylamine. Journal of Alloys and Compounds, 2019, 783: 574-582.

[46] JITTIARPORN P, BADILESCU S, SAWAFTA M N A, et al. Electrochromic properties of Sol-Gel prepared hybrid transition metal oxides-a short review. Journal of Science: Advanced Materials and Devices, 2017, 2(3): 286-300.

[47] WANG Y H, BOUCHNEB M, ALAUZUN J G, et al. Tuning texture and morphology of mesoporous $\mathrm{TiO}_{2}$ by non-hydrolytic SolGel syntheses. Molecules, 2018, 23(11): 3006.

[48] DHANASANKAR M, PURUSHOTHAMAN K K, MURALIDHARAN G. Enhanced electrochromism in cerium doped molybdenum oxide thin films. Materials Research Bulletin, 2010, 45(12): 1969-1972.

[49] ZHANG J Y, YU Z R, DU J H. Fabrication and electrochromic properties of $\mathrm{NiO}$ electrodeposit films. Journal of Chinese Electron Microscopy Society, 1997, 16(4): 451-452.

[50] WEN Y Y, ZHONG X H, HONG Y Z, et al. Fabrication of molybdenum oxides/carbon nanotube composite fibers by electrochemical deposition and its electrochemical behavior. Journal of the Chinese Ceramic Society, 2012, 40(8): 1220-1223.

[51] ZHUZHEL'SKII D V, YALDA K D, SPIRIDONOV V N, et al. Electrochemical deposition of molybdenum oxide into films of poly (3,4-ethylenedioxythiophene) conducting polymer on glassy carbon substrates. Russian Journal of Applied Chemistry, 2016, 89(8):
$1252-1260$.

[52] KÄRBER E, KATERSKI A, ACIK O I, et al. Low-cost plasmonic solar cells prepared by chemical spray pyrolysis. Beilstein Journal of Nanotechnology, 2014, 5(1): 2398-2402.

[53] DUNDAR I, KRICHEVSKAYA M, KATERSKI A, et al. $\mathrm{TiO}_{2}$ thin films by ultrasonic spray pyrolysis as photocatalytic material for air purification. Royal Society Open Science, 2019, 6(2): 181578.

[54] $\mathrm{CHO} \mathrm{J} \mathrm{S}$. Large scale process for low crystalline $\mathrm{MoO}_{3}$-carbon composite microspheres prepared by one-step spray pyrolysis for anodes in lithium-ion batteries. Nanomaterials, 2019, 9(4): 539.

[55] MOUSAVI-ZADEH S H, RAHMANI M B. Synthesis and ethanol sensing characteristics of nanostructured $\mathrm{MoO}_{3}: \mathrm{Zn}$ thin films. Surface Review and Letters, 2018, 25(4): 1850046.

[56] YU H, LI Y, ZHAO L, et al. Novel $\mathrm{MoO}_{3}-\mathrm{TiO}_{2}$ composite nanorods films with improved electrochromic performance. Materials Letters, 2016, 169: 65-68.

[57] MARTíN-RAMOS P, FERNÁNDEZ-COPPEL I, AVELLA M, et al. $\alpha-\mathrm{MoO}_{3}$ crystals with a multilayer stack structure obtained by annealing from a lamellar $\mathrm{MoS}_{2} / \mathrm{g}-\mathrm{C}_{3} \mathrm{~N}_{4}$ nanohybrid. Nanomaterials, 2018, 8(7): 559.

[58] ZHANG Y Z, HUANG Y S, CAO Y Z, et al. Synthesis and electrophotochromic properties of lithium-doped $\mathrm{MoO}_{3}$ films. Chinese Journal of Liquid Crystals and Displays, 2002, 17(3): 163-168.

[59] MAHAJAN S S, MUJAWAR S H, SHINDE P S, et al. Structural, morphological, optical and electrochromic properties of Ti-doped $\mathrm{MoO}_{3}$ thin films. Solar Energy Materials and Solar Cells, 2009, 93(2): 183-187.

[60] LAYEGH M, GHODSI F E, HADIPOUR H. Experimental and theoretical study of Fe doping as a modifying factor in electrochemical behavior of mixed-phase molybdenum oxide thin films. Applied Physics A: Materials Science \& Processing, 2019, 126(1): 372-387.

[61] KAMOUN OLFA, MAMI A, AMARA M A, et al. Nanostructured $\mathrm{Fe}, \mathrm{Co}$-codoped $\mathrm{MoO}_{3}$ thin films. Micromachines, 2019, 10(2): 138 .

[62] ZUO Y, MA D Y, XU Z P, et al. Hydrothermal growth, device preparation and electrochromic properties of nano-molybdenum oxide film. Journal of Shanghai Second Polytechnic University, 2017, 34(2): 81-86.

[63] LIU S, XU Z P, MA D Y, et al. Preparation of $\mathrm{MoO}_{3}$ thin film by $\mathrm{MoS}_{2}$ oxidation method, device assembly and electrochromic properties. Journal of Shanghai Second Polytechnic University, 2018, 35(2): 111-116.

[64] KARTEN K, HEIN A, CIOBARU M, et al. Complementary hybrid electrodes for high contrast electrochromic devices with fast response. Nature Communications, 2019, 10(1): 4874.

[65] ZHANG G, ZHANG W Z, WANG S M. Preparation of molybdenum oxide/polypyrrole composite membrane and study on its discoloration properties. Journal of Xi'an University of Technology, 2018, 38(1): $1-6,13$.

[66] LI H Z, MCRAE L, ELEZZABI A Y. Solution-processed interfacial PEDOT:PSS assembly into porous tungsten molybdenum oxide nanocomposite films for electrochromic applications. ACS Applied Materials \& Interfaces, 2018, 10(12): 10520-10527.

[67] WANG W Q, WANG X L, XIA X H, et al. Enhanced electrochromic and energy storage performance in mesoporous $\mathrm{WO}_{3}$ film and its application in a bi-functional smart window. Nanoscale, 2018, 10(17): 8162-8169.

[68] WANG J M, ZHANG L, YU L, et al. A bi-functional device for self-powered electrochromic window and self-rechargeable transparent battery application. Nature Communications, 2014, 5: 4921.

[69] CONG S, TIAN Y, LI Q W, et al. Single-crystalline tungsten oxide quantum dots for fast pseudocapacitor and electrochromic applications. Advanced Materials, 2014, 26(25): 4260-4267.

[70] LI H Z, MCRAE L, FIRBY C J, et al. Nanohybridization of molybdenum oxide with tungsten molybdenum oxide nanowires for solution-processed fully reversible switching of energy storing smart windows. Nano Energy, 2018, 47: 130-139.

[71] YANG B, MA D Y, ZHENG E M, et al. A self-rechargeable electrochromic battery based on electrodeposited polypyrrole film. Solar Energy Materials and Solar Cells, 2019, 192: 1-7. 